Int. J. Electrochem. Sci., 15 (2020) $788-802$

\title{
Sandwich-like polythioetherimide-decorated polypropylene (Celgard2400) composite separators with heat resistance and wettability for safety lithium-ion batteries
}

\author{
Haoran Xu ${ }^{1}$, Kai Han ${ }^{l}$, Meng $\mathrm{Li}^{1}$, Wen $\mathrm{Li}^{1}$, Xiaoqi Chen ${ }^{2}$, Jijun Xiao ${ }^{1, *}$, Yantao $\mathrm{Li}^{2, *}$ \\ ${ }^{1}$ School of Materials Science and Engineering, Hebei Engineering Laboratory of Aviation Lightweight \\ Composite Materials and Processing Technology, Hebei Key Laboratory of Material Near-Net \\ Forming Technology, Hebei University of Science and Technology, Shijiazhuang, 050018, People’ s \\ Republic of China \\ ${ }^{2}$ Institute of Energy Source, Hebei Academy of Sciences, Shijiazhuang, 050081, People's Republic of \\ China \\ *E-mail: jijunxiao@aliyun.com, 13903116163@163.com
}

doi: $10.20964 / 2020.01 .68$

Received: 9 September 2019 / Accepted: 30 October 2019 / Published: 30 November 2019

\begin{abstract}
We describe a sandwich-like composite separator with two sheath layers of polythioetherimide (PTEI) and a core layer of Celgard2400 to improve the heat-resistance and wettability properties of polypropylene (Celgard2400) separators for lithium-ion batteries (LIBs). The porous PTEI membranes were prepared by a wet phase inversion process and coating with Celgard 2400 via engaging a simple process without adhesive. The separators were characterized by thermogravimetric analysis, scanning electron microscopy, and contact angle measurements, and the electrochemical performances were evaluated. The results showed that the PTEI/Celgard2400/PTEI composite separators exhibited excellent thermal stabilities $\left(-37 \%\right.$ at $\left.180^{\circ} \mathrm{C}\right)$, improved wettabilities, liquid electrolyte uptakes $(298 \%)$ and ionic conductivities $\left(0.59 \mathrm{mScm}^{-1}\right)$ relative to Celgard2400. Compared to the Celgard2400 separator cell, the PTEI/Celgard2400/PTEI composite separators exhibited almost identical electrochemical properties. Such composite separators with high heat-resistance and wettability properties have a great potential for applications in high-safety LIBs.
\end{abstract}

Keywords: Polythioetherimide; Heat resistance; Composite separator; Electrochemical performance; Lithium-ion battery

FULL TEXT 
(C) 2020 The Authors. Published by ESG (www.electrochemsci.org). This article is an open access article distributed under the terms and conditions of the Creative Commons Attribution license (http://creativecommons.org/licenses/by/4.0/). 